\title{
Understanding the mobility-transformative qualities of urban park and ride polices in the UK and the Netherlands
}

\author{
Marc Dijk $^{1}$ \\ International Centre for Integrated Assessment and Sustainable Development \\ (ICIS), Maastricht University, P.O. Box 616, 6200 MD Maastricht, The \\ Netherlands \\ E-mail: m.dijk@maastrichtuniversity.nl
}

\begin{abstract}
Graham Parkhurst
Centre for Transport and Society (CTS), Faculty of Environment and Technology, Frenchay Campus, University of the West of England, Bristol BS16 1QY, UK

E-mail: graham.parkhurst@uwe.ac.uk
\end{abstract}

\section{Preferred citation}

Dijk, M. and Parkhurst, G. (2014) Understanding the mobility-transformative qualities of urban park and ride polices in the UK and the Netherlands.International Journal of Automotive Technology and Management, 14 (3/4). pp. 246-270.

\section{Abstract}

Park and Ride $(\mathrm{P}+\mathrm{R})$ has emerged as a key element of the sustainable mobility packages of many urban areas in Europe. The present article explores the impact of the introduction of $\mathrm{P}+\mathrm{R}$ on urban car mobility, especially its potential transformative impact, in two of the densest European states: the UK and the Netherlands. An analysis of six case-studies (i.e. cities) showed a degree of disconnect between stated policy aims and implementation in practice, and in some of the cases this difference was substantial. No obvious national contextual factor explaining implementation success was identified: in both contexts the (local) political will and practical tools to ensure transfer of parking capacity to $\mathrm{P}+\mathrm{R}$, were the key factors. The overall car restraining effect of $\mathrm{P} \& \mathrm{R}$ hoped for was mostly not achieved - mainly due to transfer from public transport-only trips and from cycling and because overall parking supply across city centres increased.

Keywords: park and ride; transition; sustainable mobility; urban mobility; parking; urban transport policy; transport interchange; congestion

\footnotetext{
$1 *$ Corresponding author.
} 


\section{Introduction}

Park and Ride $(\mathrm{P}+\mathrm{R})$ is a service offered to motorists enabling them to park at a location beyond an urban area, from where public transport to and from the city centre is available (or specially arranged). In recent years $\mathrm{P}+\mathrm{R}$ facilities have been increasingly developed by local authorities in industrialised states as an alternative for or addition to parking supply in the city centre. Most medium and large cities around Europe suffer from levels of motor vehicle use which result in severe traffic congestion on a daily basis (OECD, 2007). The European Commission's White Paper on Transport (CEC, 2011) calls for individual modes only to be used for the 'last miles' of journeys (para 19). Whilst recognising that the intermediate distance trips - which include the subregional movements focussed on by the present paper - are the hardest to cater for, it argues for the consolidation of the longer part of trips onto collective modes through the use of intermodal solutions (para 22).

Currently around $80 \%$ of medium and large towns in North-western Europe affirm to apply P+R schemes in one way or another (Dijk and Montalvo, 2011), but it will be argued here that whilst city governments have sought to deal with the daily tide of private motor vehicle trips, their policies have been rather ambiguous at the point of delivery. On the one hand they have aimed at accommodating the growing number of cars, by increasing parking supply; on the other hand cities have discouraged urban car use and improved public transport.

In the present paper we focus on the introduction of $\mathrm{P}+\mathrm{R}$ in the $\mathrm{UK}$ and the Netherlands from the 1970s onwards. The two countries are of wider policy interest since they have been among the pioneers of innovative parking policies (Stienstra, 2004). Moreover, they are two of the densest European states in population terms, and hence have encountered similar urban sustainability mobility problems earlier and more severely than less dense states. However, they also represent some divergence in experience around ownership of the public transport service of $\mathrm{P}+\mathrm{R}$ (private in the UK, public in the Netherlands) and also the extent to which $\mathrm{P}+\mathrm{R}$ is integrated in existing public transport lines (the norm in the Netherlands), or provided as a dedicated service (the norm in the UK, particularly for bus-based $\mathrm{P}+\mathrm{R}$ ). The two national $\mathrm{P}+\mathrm{R}$ policy contexts also show different evolutions. The Dutch trajectory is one of relatively early support from a series of national policy and funding programmes (since the early 1990s) designed to promote intermodal, integrated 'chain' mobility, including $\mathrm{P}+\mathrm{R}$. In the UK, in contrast, $\mathrm{P}+\mathrm{R}$ continued to be an essentially 'bottom-up' initiative from individual local authorities concerned about the lack of alternative means to address urban traffic growth, and providing their own capital funding; only later was $\mathrm{P}+\mathrm{R}$ eligible for national funding as part of 'package' bids by local authorities, and not until 2000 was there a national funding plan specifically promoting a national increase in $\mathrm{P}+\mathrm{R}$ schemes (Parkhurst et al., 2012).

Mingardo (2013) categorises P+R systems as either:

- remote, located in suburban residential areas and oriented towards the early interception of commuter trips; 
- peripheral, edge of town facilities, with a destination-oriented function, whose aim is to intercept drivers just before their final destinations;

- local, with a 'field function' to intercept drivers on main transport corridors at intermediate points between origin and destination.

Hitherto, most P+R schemes promoted by local authorities in the UK and NL tend to be of the 'peripheral' variety. Local and remote facilities tend to be established on national or regional railway systems and to be motivated by policies and funding initiatives above the level of the local authority. Hence we examine Amsterdam, Rotterdam, Utrecht, Bristol, Oxford and York in order to address a range of different applications of peripheral $\mathrm{P}+\mathrm{R}$ (as we discuss below) in cities that also differ significantly in their length of experience with the measure. For both countries we have chosen the pioneer of urban $\mathrm{P}+\mathrm{R}$ (Oxford, Amsterdam) and two early followers. Importantly, these cities are regarded as being amongst the most innovative within their national contexts, at least in terms of rhetoric, for their car traffic restraint policies overall. The Dutch cases range in population from 325,000 to 750,000 inhabitants, whereas the UK cases range from 135,000 to 520,000 . Our aim is to analyse the potential of $P+R$ to trigger transition to city centres with lower private car traffic through a multiple case study of urban car parking and $\mathrm{P}+\mathrm{R}$ policy.

Given the growing popularity of $\mathrm{P}+\mathrm{R}$ as a local transport tool, Karamychev and Van Reeven (2011) note that the scientific literature is relatively small, and within that part addresses planning and design issues, such as the theoretical simulation of $\mathrm{P}+\mathrm{R}$ systems or the analysis of quantitative data around the factors influencing users of P+R sites (e.g. Bos, Van der Heijden et al., 2004; Kepaptsoglou et al., 2010), and part the empirical effects and policy implications of $\mathrm{P}+\mathrm{R}$, notably the effects of $\mathrm{P}+\mathrm{R}$ schemes on urban car use and public transport demand (e.g., Parkhurst, 2000a). Rarer are studies that examine the operation of $\mathrm{P}+\mathrm{R}$ sites over a period of several years in the context of evolving city transport or parking policies and address the social and practical ambiguities in policymaking. A notable exception is Meek et al. (2010) who report on a survey of local authorities to understand the reasons behind the popularity of $\mathrm{P}+\mathrm{R}$ in the $\mathrm{UK}$, but do not extend this approach to analyse specific policy objectives and outcomes in case-study contexts.

The sociotechnical transition perspective we adopt in this paper deals with the stability of dominant practices on the one hand and the potential transformative impact of novelties on the other, which have to compete with those well-developed alternatives (Rip \& Kemp, 1998; Geels, 2005; Geels et al., 2012). This paper is one of the first instances in which the perspective is applied to transport issues (other than cleaner vehicles). In our two-layered model we put emphasis on stakeholder perspectives through a micro layer where the innovation is described through the eyes of the car travellers and the local government; two types of stakeholder most relevant here for our study of P+R. Aggregate trends of niche, regime and (relevant) landscape factors are considered in the macro layer, such as citywide parking availability and prices. So, our focus is not on functionalist aspects of travel costs and travel time but on actors in a sociotechnical context. In our 
case studies we draw evidence from documentary analysis of relevant city government policy reports (see Appendix 1).

This paper is structured as follows. Section 2 develops two hypotheses regarding the effects of P+R on urban mobility, whereas Section 3 offers explanatory case studies of urban parking developments in the six cities. Section 4 discusses similarities and differences between the case studies, addressing especially the interaction of stakeholders, regulation and infrastructure. Section 5 provides conclusions concerning the contribution of $\mathrm{P}+\mathrm{R}$ to transition in urban parking practices and formulates resultant lessons for urban planners.

\section{Urban parking strategies}

The provision of parking space is a debated issue ${ }^{2}$. Especially in larger city centres rival policy frames appear: parking policy may be seen as a key economic tool in the context of economic competition between commercial centres and hence to be promoted, or alternatively, it is viewed as one of the few engineering tools with a strong influence on car traffic and congestion. In practice, parking policy tends to reflect a compromise between these frames, through the combination of regulatory instruments: those that limit who can park and for how long and pricing structures which may seek to favour parking acts of different duration.

A third motivation, generally less publicly articulated, is the raising of revenue for local authorities from charging for parking on the highway or from investments in off-street parking capacity. In our two case-study countries, local authorities have high financial dependence on nationally-raised taxes allocated by the central governments, which retain a strong influence over how allocated funds are ultimately spent. In the context of this financial regime, parking revenues offer the rare alternative of a significant revenue stream which can be allocated to transport or non-transport budgets against locallydetermined motivations and justifications.

However, motorists' perceptions about the ease of parking emerge as a significant influence on congestion in the medium and large towns. Shoup (2005), from a review of studies, reported that between 8-74\% of motor vehicle traffic in 11 major cities was created by drivers circulating streets seeking a parking space, which on average took around 8 minutes to locate. Others found that if commuters can count on a guaranteed parking spot at their destinations, more than $90 \%$ will use the car (Kaufmann and Guidez, 1998), despite congestion. These studies illustrate how far car use is rooted in people's lifestyles, and how consequently congestion may easily boom if parking is unrestricted.

It is within this regime that $\mathrm{P}+\mathrm{R}$ offers an innovative niche solution, seeking to provide additional capacity in locations remote from the ultimate point of demand for the trip-end where land is more available and lower cost. For the commercial interests it may not be the preferred policy solution but may be a 'next best' alternative to expanding parking

\footnotetext{
${ }^{2}$ Since Adam Smith economists have regarded land invested in road infrastructure as only indirectly contributing to welfare and therefore to be reduced to an efficient minimum. This counts even more for the often inefficient use of land for free or low cost parking, as discussed by Shoup (2005).
} 
supply within the commercial centre if they accept this is unlikely to be delivered.

Travellers will tend to accept $\mathrm{P}+\mathrm{R}$ where it provides an alternative to parking constraints, for example to the commuter displaced by a residents' parking scheme, or the time-rich, money-poor shopper seeking to reduce travel costs. The acceptability of the $\mathrm{P}+\mathrm{R}$ alternative will depend much on the relative travel costs in terms of time and money, but is also influenced by attributes such as in-vehicle comfort and the opportunity to avoid the stress on cars and travellers of a congested urban environment.

For the local authorities, however, the $\mathrm{P}+\mathrm{R}$ solution relates to a number of interests, and the justifications may be varied and diverse, including a number of economic, environmental and social objectives. Successful delivery of a scheme may enhance political capital and esteem as the authority is identified as one able to introduce innovations and 'get things done'.

In order to organise our analysis of the six cities in the Netherlands and the UK, we now develop two hypotheses on how parking policy can affect the interaction of a $\mathrm{P}+\mathrm{R}$-niche and the established regime. Subsequently we test the hypotheses for our six cities ${ }^{3}$. We distinguish between policies to restrict the existing regime (push policies, 'sticks'), and policies to support the niche (pull policies, 'carrots').

\section{Push policies to restrict the existing regime}

Several empirical studies have confirmed that increasing parking prices and decreasing parking availability lead to decreased car use in the city (Young, Thompson et al., 1991; Topp, 1993; Dasgupta, Oldfield et al., 1994) ${ }^{4}$. Reducing the number of parking spaces had the greatest anticipated effect. In agreement with this, research shows that the first reason for using $\mathrm{P}+\mathrm{R}$ is a lack of sufficient parking availability within the city centre (MU-Consult, 2000). Second, data show that $40 \%$ of $\mathrm{P}+\mathrm{R}$ passengers use it because parking tariffs in the city centre are (considered) too high (MU Consult 2000). Therefore, we formulate hypothesis 1 as follows:

Hypothesis 1: strong push policies, i.e. limited parking availability in the centre and radical increase of parking tariffs, are necessary for $P+R$ to contribute to reduction of cars in the city centre. Absence of these policies precludes such a contribution.

Policies pulling to the $P+R$ niche

Bos and Molin (2006) identify seven factors that shape the satisfaction of P+R users, divided into two groups:

A. the quality of public transport connection: (1) frequency, (2) reliability, (3) cleanliness

\footnotetext{
${ }^{3}$ Each city introduced $\mathrm{P}+\mathrm{R}$ on different moment, but we focus on the decade or more after the period of introduction, in which the significant part of $\mathrm{P}+\mathrm{R}$ capacity was being developed and delivered.

${ }^{4}$ These studies are reviewed in Rye et al. (2006).
} 
B. the quality of the P+R facility: (4) safety, (5) opening hours, (6) shops or cafés available, (7) covered and heated waiting room

Frequency of connections to the city centre is considered as the most important factor from a user's perspective (Bos, Molin et al., 2005). Therefore, we propose as a second hypothesis:

Hypothesis 2: pull policies are necessary to make $P+R$ sufficiently attractive, taking into account that high frequency of connection from a $P+R$ site is an essential element.

We will re-address these hypotheses after we have analysed the cases of six cities (see maps of the cities in Figure 1).

Figure 1: Geographical overview of the P+R sites in the six cities by 2005. (Copyright $@ 1995-2010$ ESRI Data \& Maps, Europe)
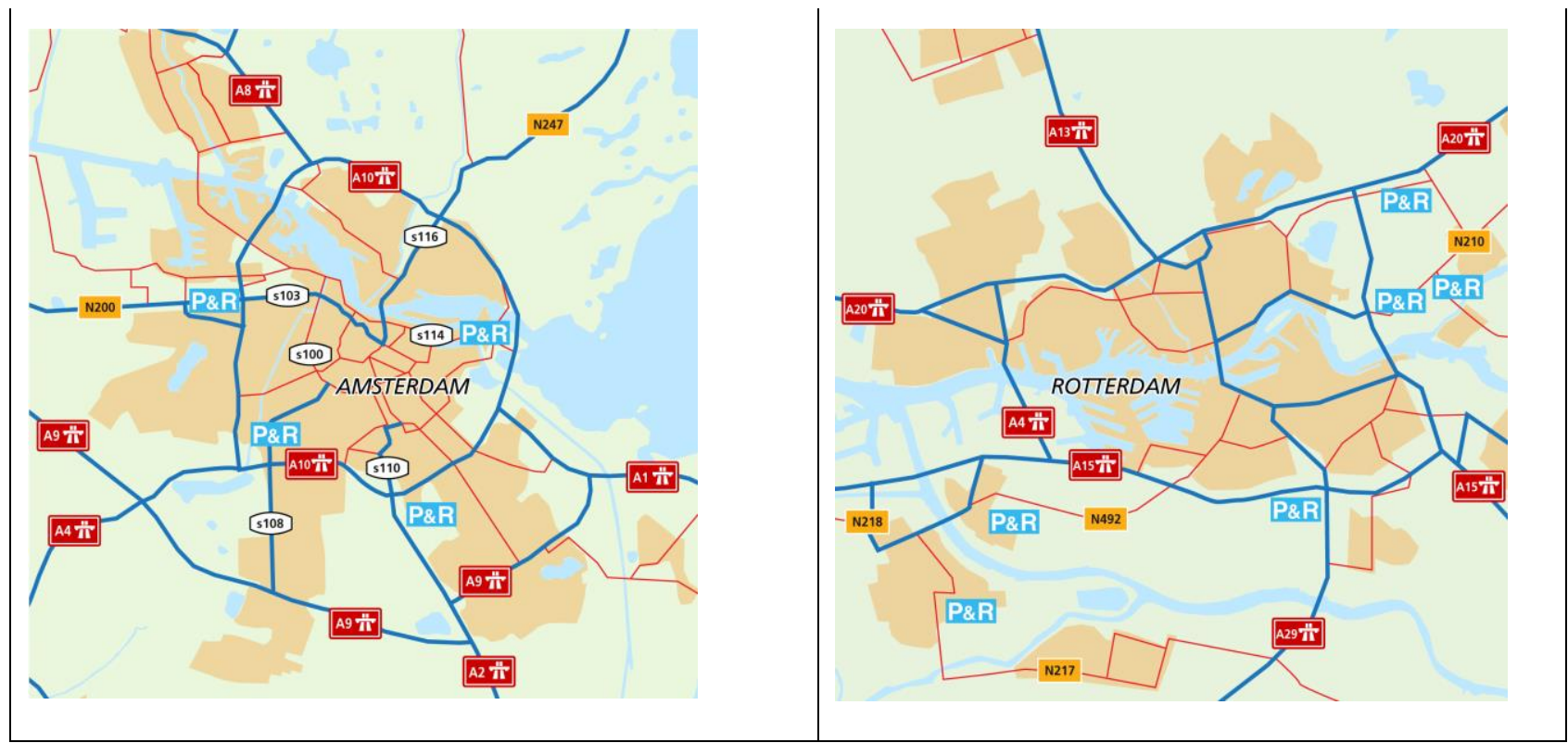


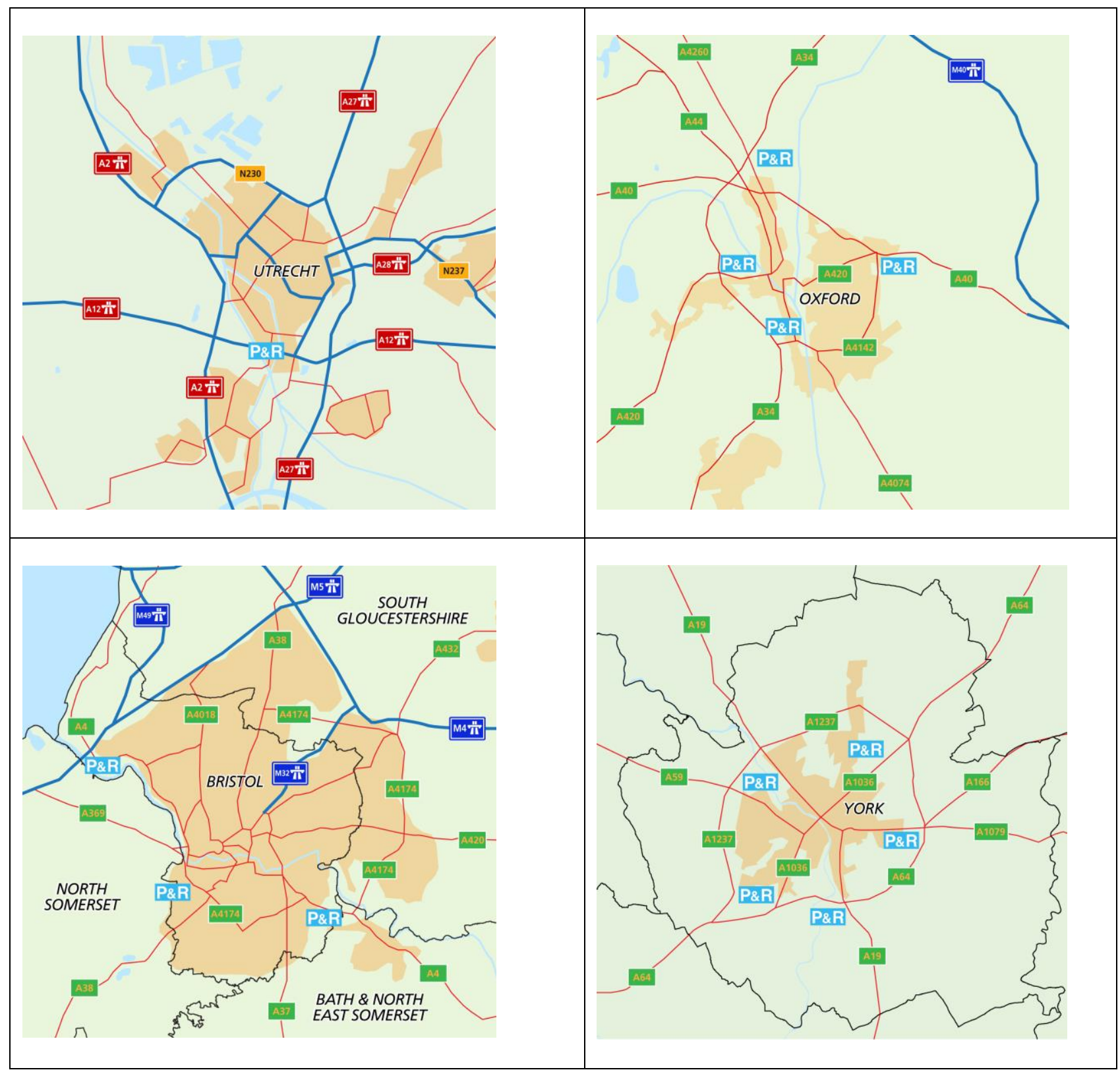

\section{Six cities}

In each case the documentary and research evidence for each city has been assessed by one of the author against specific push and pull factors as follows:

\section{Push}

Public parking cost (PPC)

Public parking constraints (with emphasis on capacity provision and length of stay restrictions) (PPR)

Access restrictions on private car traffic (AR) 


\section{Pull}

Quality of the 'Park': the P+R facility (QPR) (number of sites, parking cost etc.)

Quality of the 'Ride': Urban public transport (UPT) (with emphasis on service frequencies and fare levels)

In each case the compliance of the city with the criterion has been evaluated as low, medium or high relative to the national context. These assessments have then been critically reviewed by the other author in order to provide consistency across the analysis and across the two case-study countries. The case-study subsections below provide a summary of the evidence, whilst the final evaluations are reported in Table 1 in Section 4.

\subsection{Amsterdam}

\section{Policy context to $P \& R$}

Amsterdam has been built on and around canals, mainly during the $17^{\text {th }}$ century and this means that most of the city centre is formed by narrow streets in which the circulation of cars is difficult and where parking is generally only possible along the edge of canal banks.

Throughout the 1990s Amsterdam City Council aimed at preserving the accessibility of the city, while increasing liveability (dIVV, 2001b). It launched a new policy plan in 1994 to address ways to decrease congestion in the city centre by using a traffic management system. In the same document the council proposed a low-priced parking alternative at the border of the city centre: a P+R 'transferium'. In the latter facility motorists could transfer to both train and metro. The city council made use of funds from the national government to develop P+R for the first time. The site opened in 1996, and in the eyes of the city council it was relatively successful ${ }^{5}$. After 1999 , the authority took $\mathrm{P}+\mathrm{R}$ increasingly seriously, as is clear from reports mentioning $\mathrm{P}+\mathrm{R}$ as "an indispensable element of the accessibility of the city" (dIVV, 2001, p. 26). By 2001, it opened two new sites, and in 2005 a fourth one: all of these linked to train, metro, and (later) bikes. No bus-based sites were introduced.

\section{Importance of $P \& R$ to city transport system}

The number of $\mathrm{P}+\mathrm{R}$ users is shown in Figure 2. Motorists opting for $\mathrm{P}+\mathrm{R}$ grew from 80 in 1996 to 240 in 2000, to 450 in 2005: hence, in the context of all provided spaces within Amsterdam's inner ring, only a very small fraction (about $0.2 \%$ ). About one-third of car park users were found to be heading for a local destination and therefore did not use the public transport connection available (dIVV, 2001aa); two-thirds continued their journeys to the city centre by train or metro. A survey found an overall satisfaction score of the

\footnotetext{
${ }^{5}$ A day ticket for parking in $\mathrm{P}+\mathrm{R}$ Arena cost 5,75 euro at the time, including a return ticket to the city centre by train or metro.
} 
Arena facility was 7.5 in 1997 and 7.6 in $1999^{6}$. Around $70 \%$ had previously driven the whole trip by car, whereas about $30 \%$ used public transportation ${ }^{7}$.

\section{Balance of push and pull policies}

Amsterdam increased its parking tariffs in the city centre between 1995 and 2005 moderately, during eight of the ten years ${ }^{8}$ (see Figure 3 ). Parking supply in the city centre was roughly held stable between 1993 and 2004, at about 28,500 spaces (within the inner ring). Thus, push policies curbing the dominant urban parking regime (and indirectly promote $\mathrm{P}+\mathrm{R}$ ) were moderately strong.

Pull policies to promote $\mathrm{P}+\mathrm{R}$ were moderate in Amsterdam. The frequency and reliability of the public transport service from the sites was seen as attractive, (although not very attractive), while facilities at or near the sites for users (shops, cafés, making waiting more attractive) scored poorly. No special collaborative efforts were applied to stimulate the use of $\mathrm{P}+\mathrm{R}$ over the decade (such as collaboration with companies or shops).

\section{Accumulated outcomes}

The average parking pressure in 2004 was $80 \%$ (which was fairly stable after 1998, in a context of no change in parking supply 1995-2005). The total number of car-km travelled in the city centre decreased between 1995 and 1997 (by 9 percentage points), due to the introduction of the new parking tariffs. After further extension of the charged areas, parking acts in the city centre increased again (after 1998). In 2001, the city government estimated, however, that without parking taxes car use within the city ring would have been 13\% higher than outturn (dIVV, 2001b). After 2001 the goal was set to reduce car use in the city centre by $25 \%$, and this was reached by 2005 . The share of visitors using public transportation grew to $30 \%$. In other words, the restricting central parking regime pushed most people into public transportation (for the whole trip), and few into P+R use.

\footnotetext{
${ }^{6}$ This is fairly high, but we acknowledge that assessing the opinion of actual users gives a biased view on the opinion of car travellers in general: it does not measure all the dissatisfaction of non-users, or drivers that tried once but did not return.

7 Amsterdam has nine train stations (with the Central Station transferring about 280,000 travellers a day) and a good tram and underground public transport system that gives the opportunity to easily reach most of the city centre.

${ }^{8}$ In the report of 2001 (dIVV, 2001) it was made explicit that a moderate increase was chosen, to avoid unwanted effects on the local economy or social acceptance (in case of high increase), and too little effect on decrease of unnecessary car use (in case of low increase).
} 
Figure 2: Growth in use of Amsterdam P+R sites (Source: dIVV)

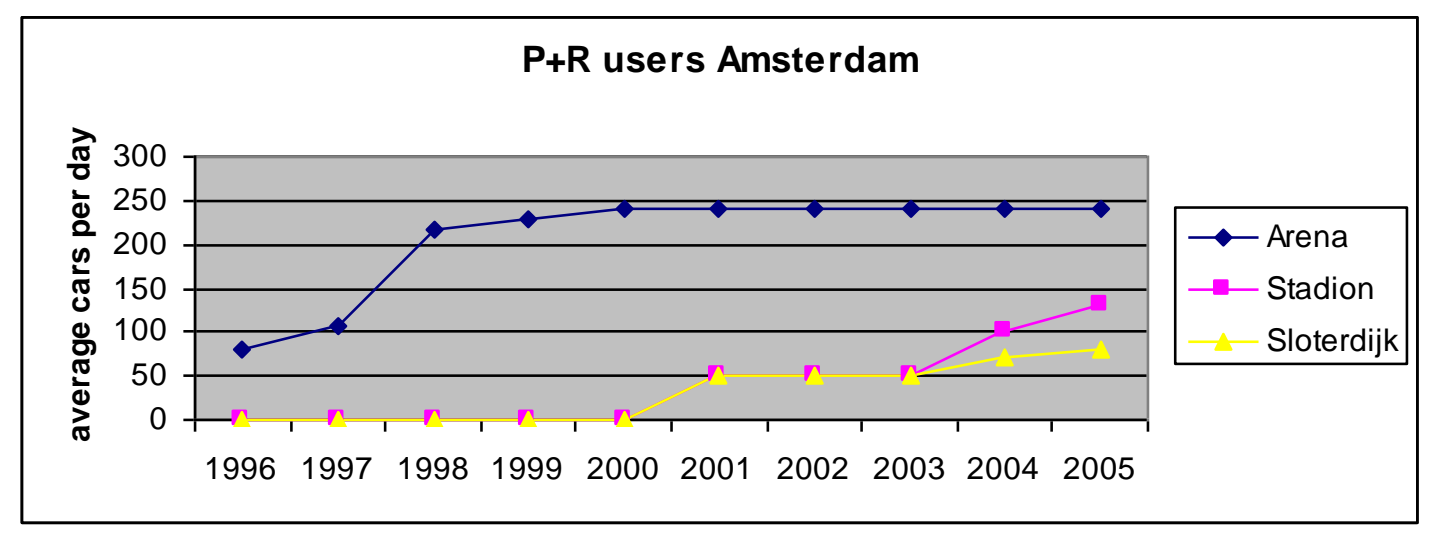

Figure 3: Hourly parking tariffs in Amsterdam, Rotterdam and Utrecht (1995-2005). Tariffs in Rotterdam are averages (since they vary between streets and times of the day).

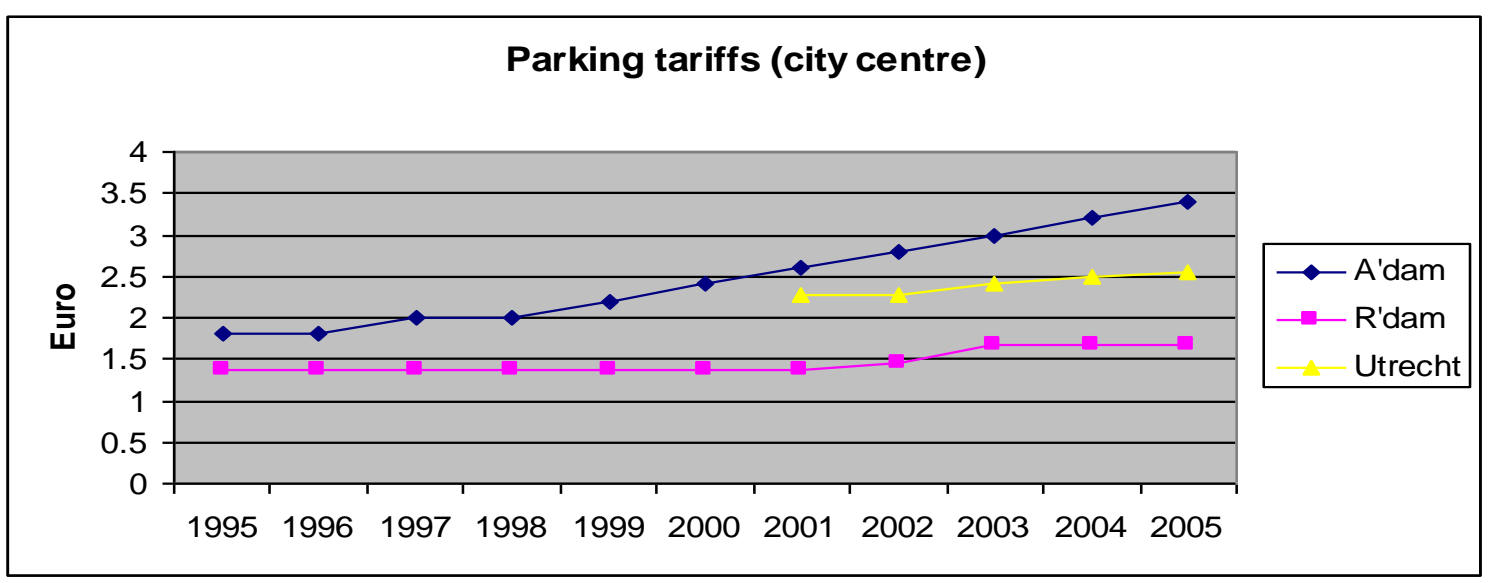

\subsection{Rotterdam}

\section{Policy context to $P \& R$}

In contrast to Amsterdam, Rotterdam has a modern and spacious road network, most of it rebuilt after severe damage during the Second World War. In the 1980s, Rotterdam's city government had developed two types of $\mathrm{P}+\mathrm{R}$ sites: those with a local function and those with a regional function. The first type was built solely as parking lots near public transport stations (especially metro stations) for local users ${ }^{9}$. The second type contains (larger) sites attuned to car drivers from the region that visit the city centre (also linked to metro and train stations). In the beginning of the 1990s the authority re-stressed the role and operation of $\mathrm{P}+\mathrm{R}$ sites in their transport policy (Gemeente-Rotterdam, 1993). The sites were upgraded to provide a more attractive opportunity for commuters.

Importance of $P \& R$ to city transport system

\footnotetext{
${ }^{9}$ On most $\mathrm{P}+\mathrm{R}$ sites in Rotterdam parking is free of charge as long as the motorist can show his public transport ticket.
} 
Motorists in Rotterdam are supplied with a spacious principal road roadwork throughout much of the city, and ample parking supply. In addition, the metro system is well developed, and there are numerous train, tram and bus lines. More than 2,500 motorists each day (Figure 4) combine the two modes, parking at one of the six regional $\mathrm{P}+\mathrm{R}$ sites (Gemeente-Rotterdam, 2007). Mingardo (2008) studied the way P+R users previously travelled. He found that, at most sites, $33 \%$ of the current users previously travelled by public transport or by bike. This means that one third of the users do not represent reduced car trips to the city centre. Therefore, other things being equal, the interception of car traffic is equivalent to around 1,075 fewer cars in the central area (versus around 300 in Amsterdam).

\section{Balance of push and pull policies}

Parking tariffs in the city centre were somewhat increased over the decade from 1995 (see Figure 3), in a way insufficient to have been a major incentive for $\mathrm{P}+\mathrm{R}$ use, as an alternative to parking downtown. The total number of parking places in the city centre was not limited between 1995 and 2005, but increased around 10-15\%, within the limit of what was called 'the environmental liveability of local neighbourhoods'. Thus, push policies leading away from the dominant urban parking regime (and indirectly promoting $\mathrm{P}+\mathrm{R}$ ) were weak.

The coverage and quality of public transport means that pull policies to promote $\mathrm{P}+\mathrm{R}$ were moderately strong in Rotterdam. Evaluation studies of the $\mathrm{P}+\mathrm{R}$ sites suggest that the quality of the facilities were seen as satisfactory. Regarding the frequency of public transport services at the sites, the fast and reliable underground metro system emerged as an already optimal solution.

\section{Accumulated outcomes}

The net effect of the practices adopted by road users resulted in a mild increase in motor vehicle traffic between 1995 and 2005, although the area inside the inner city cordon was an exception, where demand in 2005 was back at the 1995 level (Gemeente-Rotterdam, 2005). The total number of users of public transportation (i.e. bus, tram and metro) in Rotterdam decreased from 172 million in 1995 to 160 million in 2005 (source RET). The contribution of $\mathrm{P}+\mathrm{R}$ to reduction of car trips to Rotterdam centre was low (around 1 or 2 $\%)^{10}$.

\footnotetext{
${ }^{10}$ The total number of daily car parkers in the city centre is estimated 50 to 100 thousand, while $\mathrm{P}+\mathrm{R}$ intercepts around 1075 car travellers to the city centre.
} 


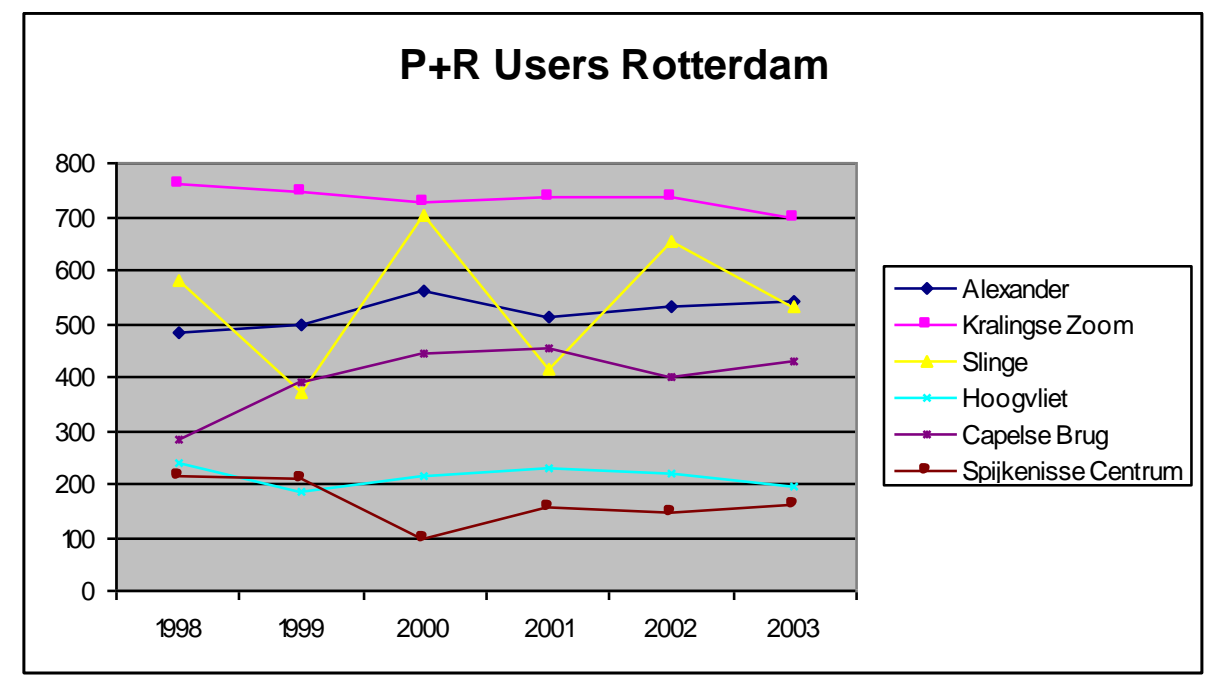

\subsection{Utrecht}

\section{Policy context to $P \& R$}

The city government records that "Utrecht has a parking problem, meaning that demand for parking spots is higher than supply" (Gemeente-Utrecht, 2003a, p.7). The prime objectives for the city's transport policy were identified as maintaining or increasing accessibility and liveability. These should, however, respect the freedom of the car driver: "[we aim to] meet the demand for car mobility of our citizens: 'car mobility is okay'”' (Gemeente-Utrecht, 2003b, p.10). In 1998 the authorities started a P+R experiment at Galgenwaard, called 'Shopping-Express'. During the peak shopping hours only (Thursday night and Saturday), the parking lot of the football stadium was used, served by a low-cost shuttle bus linking the city centre. On average 200-300 hundred cars were parked at the stadium, with the main reason for use being to avoid driving in the busy city centre. This initial success encouraged policymakers to develop positive attitudes towards $\mathrm{P}+\mathrm{R}$ in general. In 2000, when the national government offered a subsidy, P+R Westraven was built on the southern ring road. It included 750 places, connected by (existing) high-speed tram. The daily fee to park was $€ 7.50$, decreased to $€ 3.50$ in 2007.

\section{Importance of $P \& R$ to city transport system}

Motorists to Utrecht were not attracted to the large P+R facility: only a few dozen chose to park cars there. An important reason why drivers favoured parking in the centre was that there were still areas near the town centre where it was possible to park for free. Another was that finding a parking space in the city centre was made easier, through an automatic system (PRIS) indicating where there was available off-street capacity. Alternatively, travellers chose for public transport all the way: Utrecht has the largest train and bus station in the Netherlands and an extensive bus network throughout the city. 


\section{Balance of Push and pull policies}

From the end of the 1990s the city government upgraded central urban parking. Large sums were invested in building new garages near the inner city (Gemeente-Utrecht 2003 b), extending the parking capacity by more than 1,000 spaces contributing to at 10 $15 \%$ increase in supply 1995-2005, followed by the introduction of the parking guidance system in 2000. Parking tariffs were kept moderate (intermediate between Rotterdam and Amsterdam, see Figure 3). At the same time, the budget for $\mathrm{P}+\mathrm{R}$ was limited, and required to break even in the longer term, so that Westraven was only developed due to the availability of the national subsidy. All in all, both pull and push policies for $\mathrm{P}+\mathrm{R}$ in Utrecht were weak over the period.

\section{Accumulated outcomes}

Little was done about the low use of the $\mathrm{P}+\mathrm{R}$ facility for several years. More recently, local government policy has departed from the principles of using $\mathrm{P}+\mathrm{R}$ to intercept city centre car traffic by stimulating use of the car park by firms located in the vicinity of the site, instead of preserving its use for transport to the city centre. As a result, it is not surprising that the facility did not decrease car use in the city centre.

\subsection{Oxford}

\section{Policy context to $P \& R$}

Oxford City Council adopted bus-based P+R at the beginning of the 1970s as part of 'balanced' or 'integrated' transport strategy. At a time of growing public concern about the acceptability and affordability of urban highway construction to provide for free-flow traffic the council accepted the need for car traffic restraint for the first time.

It expected $\mathrm{P}+\mathrm{R}$ to contribute to curbing the rising local environmental consequences of car use, road congestion, and declining conditions for pedestrians. Therefore, it developed bus $\mathrm{P}+\mathrm{R}$, with new shuttle bus services, as a relatively cheap and pragmatic policy to adopt. Over 30 years the system has been expanded to five sites offering a total of approximately 5,000 spaces and higher-specification buses and site facilities. For most of the history of the system users parked for free and paid for bus travel. However, parking charges were introduced in recent years in response to public spending cuts and in order to limit very long-stay parking by vacationers.

\section{Importance of $P \& R$ to city transport system}

Many of the towns within the Oxfordshire subregion have lost their rail connections. Travellers therefore have $P \& R$ and inter-urban bus services as the main alternatives to city centre parking. Urban and interurban bus services together have a higher modal share for accessing the city centre than private car use.

Frequent (10-30 minute headway) dedicated bus services are provided to the P\&R sites. When P\&R was initially developed, very basic car park facilities and buses were provided in order to maintain financial viability. Cost differentials with city centre parking ensured 
these basic facilities were judged as acceptable by users, and around $10 \%$ of inbound motorists opted for P+R use by the early 1990s (Parkhurst and Stokes, 1994), although conventional public buses remained far more important in terms of total demand. A decade later, with the $\mathrm{P}+\mathrm{R}$ scheme expanded in capacity, further restrictions and higher charges have been introduced in the city centre, and higher quality facilities offered on the $\mathrm{P}+\mathrm{R}$ operations.

In combination with a strongly enforced greenbelt around Oxford, $\mathrm{P} \& \mathrm{R}$ can be identified as a key part of a transport policy which has facilitated the development of commuting from dormitory towns in its subregion and supported economic growth in the city itself.

Figure 5: Modal choice and daily public parking cost evolution in Oxford

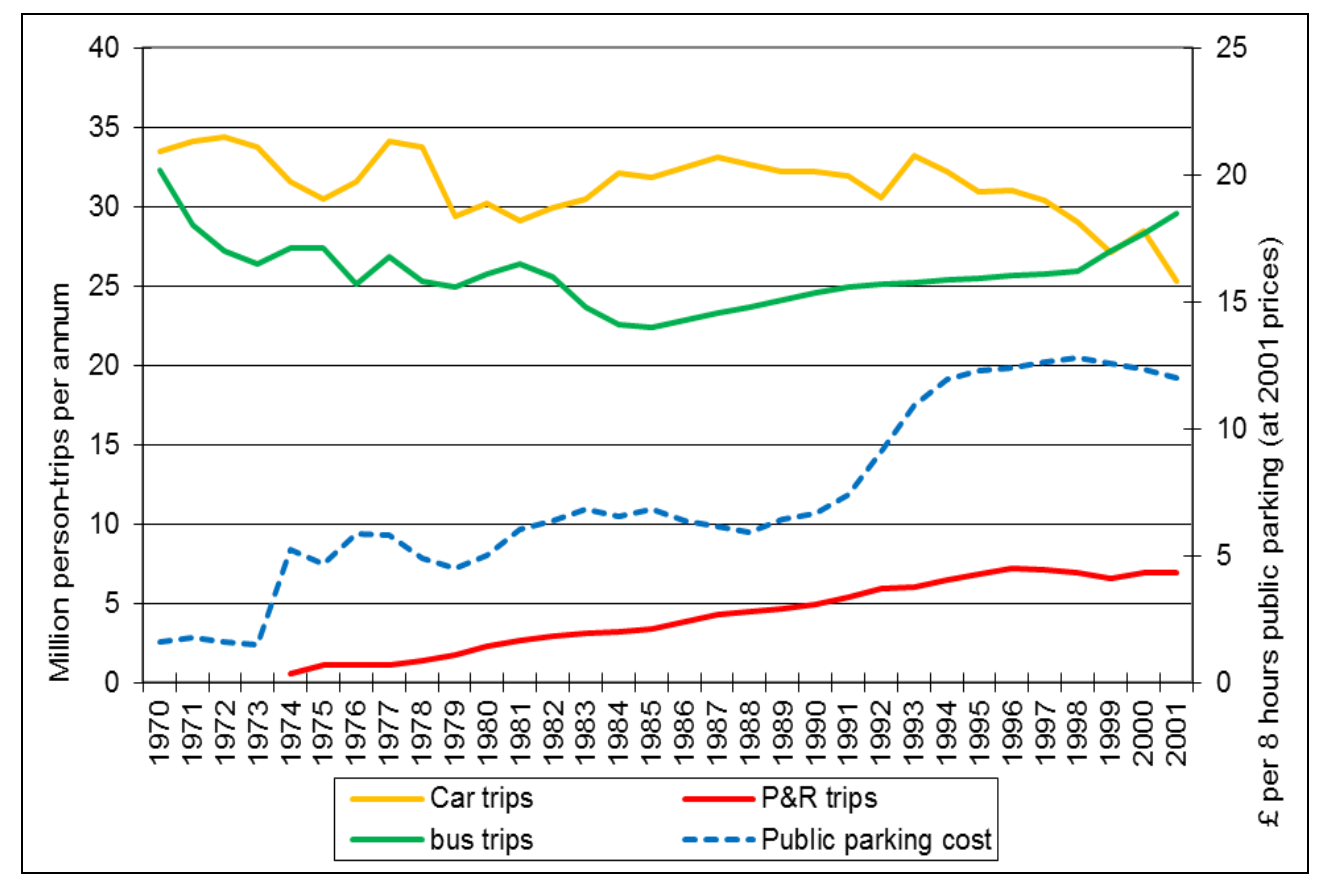

\section{Balance of push and pull policies}

A key factor of the Oxford policy intention was to link strong push and pull elements by increasing off-street parking charges (Figure 5), particularly for long stays, and using the revenues to support $\mathrm{P}+\mathrm{R}$ operations. Another effective push policy operated by Oxford City Council used planning permission conditions to require developers to contribute to the cost of public $\mathrm{P}+\mathrm{R}$ capacity instead of providing private off-street capacity in individual developments. A further potentially powerful policy was to limit the provision of public parking in the city centre (Parkhurst, 1993). However, this policy was only moderately effective in restraining motor vehicle traffic levels; a growing share of city centre motorists were either passing through the centre or had access to private, off-street parking. There was also an increased share of shorter stays, due to the increased parking charges in public parking spaces being particularly deterrent for long stays.

\section{Accumulated outcomes}


By 1992 the total amount of parking available for trips to the city centre (including P+R) had increased, although that available to the general public in the central area had fallen. Off-street parking was reduced by around $10 \%$, but most of the on-street capacity was eliminated, so that an overall availability of more than 10,000 spaces in 1966 was reduced to less than 4,000 (Parkhurst, 1993). However, private off-street parking capacity nearly doubled in the same period, to more than 10,000 spaces, despite restrictive development control policy, apparently as a result of long-standing off-street parking 'rights' being used more intensively.

These changes in parking provision were associated with a $20 \%$ decline in car traffic and an increase in bus use at the end of the 1990s (Figure 6). However, a key factor here was a reinvigorated traffic restraint policy which focussed on restricting through-traffic in several central streets. $\mathrm{P}+\mathrm{R}$ use was in fact stable in this latter period whilst central parking charges actually fell in real-terms.

Figure 6: Parking capacities serving Oxford and York city centres before and after the adoption of car traffic management policies. Source: Parkhurst (1993)

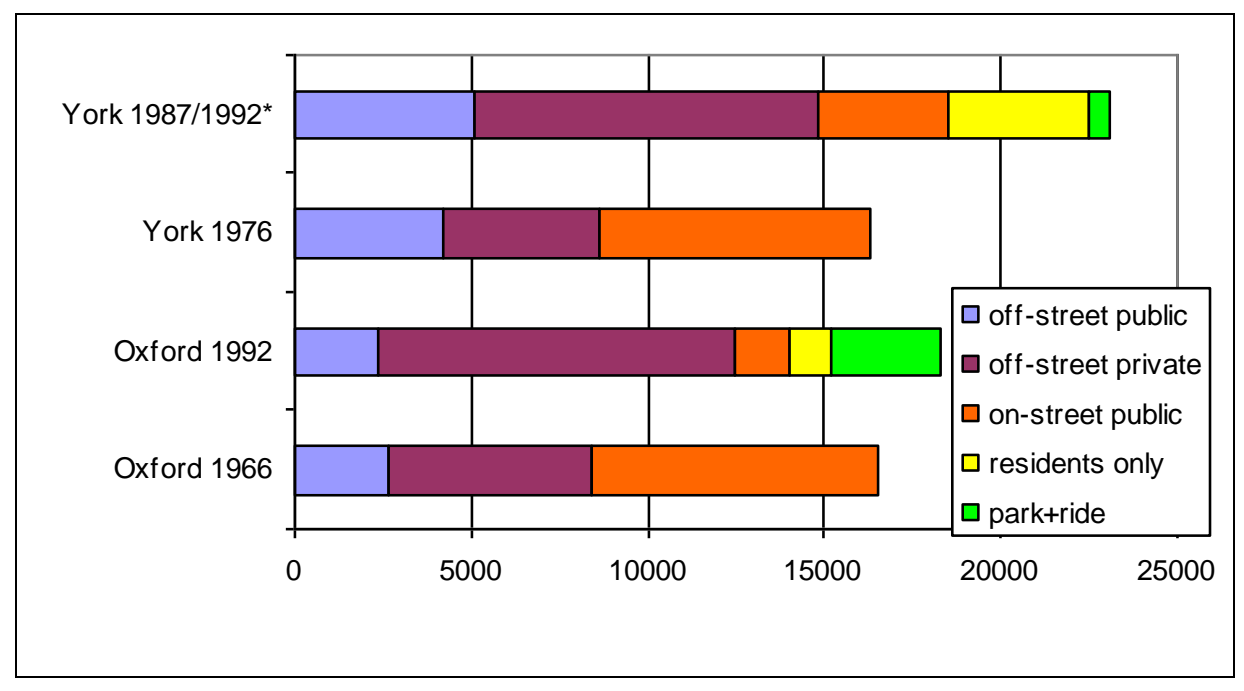




\subsection{York}

\section{Policy context to $P \& R$}

York is regarded as one of the most successful examples of wide-area 'retrofit' pedestrianisation in the UK. Whilst congestion remains a relevant issue, the city council has managed the worst effects of car use on the city centre economy relatively effectively. Combined with the rural origins of many of the frequent users of the city centre and planned strategic growth, the highest priority for $\mathrm{P}+\mathrm{R}$ policy has been to contribute to economic objectives, with a medium contribution to reducing congestion and a small contribution to improving air quality (YCC, 2006b).

Following the implementation of a partial reorganisation of English local government in certain areas, York City Council was established as a unitary authority with control over the territory immediately beyond the perimeter of the urban area. This had the result that a single local authority had the responsibility for delivery of short-range $\mathrm{P}+\mathrm{R}$, whereas previously the City had statutory responsibility for development control but strategic planning and transport policy was the responsibility of the higher county tier of government. In this context York City Council has pursued one of the most intensive $\mathrm{P}+\mathrm{R}$ policies in the UK, delivering 5 sites in less than 15 years (1991-2005), with a onethird expansion in capacity in the final five years of this period, to a total of around 3,500 spaces. Whilst operating costs were covered from user fares in recent years, significant capital costs for new sites were designated: $\mathrm{P}+\mathrm{R}$ expansion was in fact the largest item in the Council's transport capital spend from 2001/02 to 2005/06: $£ 8.5$ billion of a total $£ 28$ billion. Unlike Oxford, there are no parking charges at York sites; users pay for bus travel. However, in order to improve financial performance, a discounted bus fare $(27 \%$ of full fare) has been introduced for citizens who hold a free-travel bus pass on grounds of being of pensionable age or mobility impairment.

\section{Importance of $P \& R$ to city transport system}

Unlike Oxford, which is embedded in the southeast economic core, York has a relatively rural location, as a central place serving a large hinterland. Its subregion has been less subject than that of Oxford to rail disconnections. Extra-urban buses are less well developed, although urban services are attractive and innovative.

The supply of five $\mathrm{P}+\mathrm{R}$ sites over a relatively short period has made it an attractive option for car travellers, with around 3 million return trips per annum being made by 2009 (YCC, 2009a).

\section{Balance of push and pull policies}

Parking policy represents a medium level of push in York: supply policy places a cap on off-street public car parking in the city centre at 2002 levels (5,100 spaces) (2006a). As in Oxford, a parking regime based on length-of-stay restrictions and tariffs which favour short and medium stays has been effective in reducing demand for commuter parking. Some parking capacity has also been transferred from the city centre to $P \& R$, although overall capacity has grown significantly (see Figure 6) and the increases in parking 
charges for the majority of car park users over the period 2005-9 were significantly below the rate of general inflation (YCC, 2009a).

In contrast, pull policies have been strong, seeking to make the $\mathrm{P}+\mathrm{R}$ sites and shuttle services high-quality and financially attractive. The buses operate at up to ten-minutes headways and travel is relatively low cost, with discounts for frequent users, and free travel for children accompanying adults.

\section{Accumulated outcomes}

The increase in $\mathrm{P}+\mathrm{R}$ use must be placed in the context of an increase in conventional bus use of around 50 percentage in the decade from 2000, and more than twice as many return trips are made by non $\mathrm{P}+\mathrm{R}$ bus than $\mathrm{P}+\mathrm{R}$ bus (YCC, 2009b).

During the five years from 2000 when P+R capacity increased by a third, motor vehicle traffic in the York administrative area rose overall by 3\% in the 12-hour day, although this was the net effect of a 3\% reduction in the morning peak hour and $2.4 \%$ increase in the inter-peak period. Approaching 10\% modal shift away from private car specifically for trips to access the city centre was evident (again with larger shifts occurring in the peak periods). One explanation for these data is travellers' responses to the nature of the parking regime: demand for city centre parking fell overall by 30\% 2000-2005 (YCC, 2006a). Hence, a 10\% reduction in council-controlled off-street parking supply to a total of 3,500 spaces as a result of redevelopment has not resulted in scarcity of demand, and total parking revenues fell along with patronage, by around $10 \%$ or $£ 3$ million in the period 2006/7-2008/9 (YCC, 2009a).

\subsection{Bristol}

\section{Policy context to $P \& R$}

Along with Nottingham, Bristol was one of two pioneers of bus $\mathrm{P}+\mathrm{R}$ as a solution for medium-size cities in England. Bristol is characterised by hilly terrain and a city centre which, like Rotterdam, suffered wartime destruction and was redeveloped with shopping precincts and an extensive road system including an urban motorway in the post-war period. A combination of physical, economic and institutional factors has resulted in Bristol arguably becoming the most car dependent of the ten largest urban areas in Britain, with the lowest motor vehicle traffic speeds outside London and a public transport modal share of less than $15 \%$.

Over three decades different tiers of local authority led unsuccessful policy initiatives to re-introduce light rail and adopt city centre road pricing. $\mathrm{P}+\mathrm{R}$ was introduced as part of a package of shorter-term measures including intermittent bus priorities on the highways. Three sites have been opened in 1993, 1997 and 2002, with a total of 3,300 spaces. Users pay for bus travel but parking is free. The bus service to the youngest (and smallest) site, Portway, is not dedicated but also marketed as a 'walk to bus' service to those residential areas it passes through. The primary objective of policy was reducing peak-hour congestion, although secondary objectives of accessibility, road safety and air quality benefits were also intended (WoEP, 2006). 


\section{Importance of $P \& R$ to city transport system}

The Bristol urban area, with a population of 520,000, is much larger than Oxford or York. Rail-based $\mathrm{P}+\mathrm{R}$ is typically more suited to this scale of city, as segregated rail corridors are particularly advantageous in comparison with metropolitan bus services. In the case of Bristol, though, suburban rail services are limited in terms of network extent and capacity, with both train schedules and station car parking management being oriented towards serving regional and national movements rather than local needs.

Therefore demand for bus $\mathrm{P}+\mathrm{R}$ has generally followed the provision of facilities. Considering both $\mathrm{P}+\mathrm{R}$ sites in Bristol and in the neighbouring city of Bath, the Joint Local Transport Plan 2008 Progress Review noted patronage had risen faster than targeted (by 15\%) in the previous five years (WoEP, 2008). The majority of this demand is from travellers who perceive their alternative travel option to be drive-by-car to the city centre. However, approaching half of users at the Bath Road site and a third at the Long Ashton site were found from surveys in the 1990s to have transferred from public transport. Around a half of users to the Bath Road site were also travelling from origins within $10 \mathrm{~km}$ (BCC, 1996; BCC/NSC, 1997). The site is located adjacent to dense suburbs and on the corridor between Bristol and the neighbouring city of Bath, just $10 \mathrm{~km}$ to the southeast. These modal shifts from public transport and the attraction of shortrange trips to $\mathrm{P}+\mathrm{R}$ can be understood as the result of high rail fares and peak-hour crowding on trains, whilst non- $\mathrm{P}+\mathrm{R}$ bus fares are also higher than $\mathrm{P}+\mathrm{R}$ fares.

\section{Balance of push and pull policies}

$\mathrm{P}+\mathrm{R}$ provision has been linked to a parking policy to transfer long-stay parking in particular from the city centre to an expanded number of $\mathrm{P}+\mathrm{R}$ sites $(\mathrm{BCC}, 2000)$ using deterrent tariff structures for public parking and development control measures for private parking. In practice, however, the policy has faced two key constraints. First, Bristol City Council (BCC) only controls around half of the public off-street parking. Second, the city centre faces significant economic competition from a large shopping mall (Cribbs Causeway), located on the periphery of the Bristol urban area with 7,000 free, unrestricted parking spaces. Its presence is acknowledged as having a significant competitive impact on parking policy (WoEP, 2006): concern about economic competition resulted in BCC granting planning permission for a new shopping centre, Cabot Circus, in the city centre, which opened in 2008 with 2,600 additional charged parking spaces, representing a $25 \%$ increase in public off-street city centre supply. In 2011, Bristol's parking charges were identified by a consumer affairs organisation to be typical for a city of its size. Overall, push factors for modal shift can be regarded as moderate, with available capacity compensating for price, whilst pull factors are weak-tomoderate, limited by $\mathrm{P}+\mathrm{R}$ capacity but with growing effectiveness of public transport priority.

\section{Accumulated outcomes}

The policy intention to transfer long-stay parking to the periphery of the city $(\mathrm{P}+\mathrm{R})$ has had some success, although total parking capacity in the city centre has risen due to new 
retail development, whilst the share controlled by BCC has fallen. The local policy target for motor vehicle traffic into Bristol city centre is for 'zero growth'. A $10 \%$ reduction in flow in fact developed over the four years to 2007-8, although this was partially reversed in 2008-9. Conventional bus patronage in the subregion rose above target in the same period (WoEP, 2008). However, there is evidence that $\mathrm{P}+\mathrm{R}$ is competing with public transport, rather than significantly expanding its use, as a large minority of users would have otherwise used public transport.

\section{Discussion}

The outcomes of the push and pull policies deployed in the six cities are summarised in Table 1.

Comparing the six cities, we find no one combined strong push with strong pull policies, and this suggests that none of the cities maximized the potential to transfer parking to $\mathrm{P}+\mathrm{R}$. Nevertheless, Amsterdam came closest and Oxford and York also apply relatively strong pressure on city centre car traffic. In the case of Amsterdam and Oxford, high city centre parking charges and scarce availability were the key features, and in the case of York, a particularly attractive $\mathrm{P}+\mathrm{R}$ offer combined with relatively strong city centre access restrictions. Rotterdam emerged as an intermediate case, where limited disincentives for city centre parking to some extent counteracted the strength of the public transport offer. In the case of Bristol city centre parking costs are typical, but public transport promotion has yet to have sufficient effect due to insufficient segregation for a medium-size city. Utrecht presented the lowest pressure on car use, with the policy rhetoric insufficiently translated into delivery, with weak push and pull signals.

The analysis explains well the effectiveness of the $\mathrm{P}+\mathrm{R}$ (push and pull) policies to the pressure on city centre car traffic, but reaching general conclusions on traffic reduction is more problematic. After all, the relation of $\mathrm{P}+\mathrm{R}$ use to actual reductions in traffic is not a straightforward relationship, but depends partly on factors such as the economic activity context and effectiveness of other traffic management measures, such as restrictions on through-traffic and the promotion of public transport in general. Hence, the cities with the greatest reduction in traffic - Amsterdam and Oxford - achieved this more through increasing modal shift from car to conventional public transport rather than to $\mathrm{P}+\mathrm{R}$ use. York was notable in that $\mathrm{P}+\mathrm{R}$ does seem to have been a specific factor resulting in traffic reduction in the peak period, but this was accompanied with traffic growth overall as car owners took advantage of available short-stay car-parking in the inter-peak. 
Table 1: Effectiveness of deployment of push and pull policies in the six cities (with the abbreviations referring to (see Section 3): Public parking cost (PPC); Public parking constraints (PPR); Access restrictions on private car traffic (AR); Quality of the 'Park': the $P+R$ facility (QPR); Quality of the 'Ride': Urban public transport (UPT).

\begin{tabular}{|c|c|c|c|}
\hline City & $\begin{array}{l}\text { Push Policies (regime } \\
\text { restriction) }\end{array}$ & $\begin{array}{l}\text { Pull Policies (niche } \\
\text { promotion) }\end{array}$ & $\begin{array}{c}\text { Combined pressure on } \\
\text { car traffic }\end{array}$ \\
\hline Amsterdam & $\begin{array}{l}\text { High PPC } \\
\text { High PPR } \\
\text { Low AR }\end{array}$ & $\begin{array}{l}\text { Medium QPR } \\
\text { Medium-High UPT }\end{array}$ & Medium-High \\
\hline Oxford & $\begin{array}{l}\text { High PPC } \\
\text { Medium PPR } \\
\text { Low AR }\end{array}$ & $\begin{array}{l}\text { Medium-High QPR } \\
\text { Medium UPT }\end{array}$ & Medium-High \\
\hline York & $\begin{array}{l}\text { Medium PPC } \\
\text { Low PPR } \\
\text { Medium AR }\end{array}$ & $\begin{array}{l}\text { Medium-High QPR } \\
\text { Medium-High UPT }\end{array}$ & Medium-High \\
\hline Rotterdam & $\begin{array}{l}\text { Low PPC } \\
\text { Low PPR } \\
\text { Low AR }\end{array}$ & $\begin{array}{l}\text { High UPT } \\
\text { High QPR }\end{array}$ & Medium \\
\hline Bristol & $\begin{array}{l}\text { Medium PPC } \\
\text { Low PPR } \\
\text { Low AR }\end{array}$ & $\begin{array}{l}\text { Medium QPR } \\
\text { Low UPT }\end{array}$ & Medium-Low \\
\hline Utrecht & $\begin{array}{l}\text { Low PPC } \\
\text { Low PPR } \\
\text { Medium AR }\end{array}$ & $\begin{array}{l}\text { Low UPT } \\
\text { Low QPR }\end{array}$ & Low \\
\hline
\end{tabular}


The role of subregional and regional public transport has been noted in the case-study summaries but not formally included in the push and pull analysis in Table 1 . The importance and direction of influence of this factor is important, but much depends on the way in which $\mathrm{P}+\mathrm{R}$ is integrated with the public transport system: whether road or rail public transport, relative location with respect to typical user origins and the city centre, and the charging structure (Parkhurst, 2000b; Mingardo, 2013). In practice we see from the case-studies, particularly in the UK where the 'ride' is generally a dedicated express bus separate from the mainstream public transport system, that $\mathrm{P}+\mathrm{R}$ has the potential to compete with policies for meaningful increase in public transport use as well as to complement them.

Relative pricing is a key factor in this relationship. Local authorities generally recognise and act upon the need for there to be a sufficient differential between total $\mathrm{P}+\mathrm{R}$ costs and total city centre access costs if the $\mathrm{P}+\mathrm{R}$ sites are to be used, but the wider relationships may not be addressed. As a result, switching from long-range public transport in order to take advantage of highly attractive urban periphery $\mathrm{P}+\mathrm{R}$ may occur: this can most easily be countered by ensuring $\mathrm{P}+\mathrm{R}$ is offered at an intermediate price, but local authorities may be reluctant to increase $\mathrm{P}+\mathrm{R}$ and city centre parking charges as a policy measure to influence behaviour. Where higher city centre parking and user $\mathrm{P}+\mathrm{R}$ charges have been seen in recent years that has generally been a reflex, pragmatic response to deteriorating public finances, or on occasion to tackle some specific local issue of use of the $\mathrm{P}+\mathrm{R}$ lot by travellers accessing destinations in its vicinity, rather than a policy-driven attempt to achieve an integrated, regional transport policy.

Hence we find that $\mathrm{P}+\mathrm{R}$ makes an important symbolic contribution in cities to the development of a car traffic restraint frame, which builds consensus around the idea that alternatives for car-dependent travellers are being provided. There is however a practical limitation to such a symbolic contribution. $\mathrm{P}+\mathrm{R}$ is often presented as a tool of 'integrated' transport planning, in that it combines the use of different modes. However, it is not integrationist in the wider sense of reducing car traffic demand in a consistent way over time and space: traffic growth occurred in some of the cities outside the city centre and additional trips to $\mathrm{P}+\mathrm{R}$ can be assumed to contribute to this trend, notably in Bristol where there was high modal shift from public transport to P\&R; in Utrecht a poorly demanded $\mathrm{P}+\mathrm{R}$ facility became additional local parking supply; in York reduced demand in one part of the day was exchanged for increase in another ${ }^{11}$.

Related to this particular meaning of 'integration' is the finding that $\mathrm{P}+\mathrm{R}$ represented in each of the six cities an overall increase in parking supply for the city centre - even if introduced alongside greater constraints on which travellers can use which capacity and when - suggesting that additions in parking capacity are generally easier to achieve than reductions. To different extents in the six case-studies then, we find echoes of Kauffman's (2000) conclusion that: promoting the use of public transport by improving

\footnotetext{
${ }^{11}$ Hilbers et al. (2009) also find through a modeling exercise that, ceteris paribus, more public transport services increase the use of public transport but hardly decrease car use. It attracts rather users that used to walk, bike or established users to travel more. Overall, the effect on emissions, safety and noise was neutral or negative.
} 
it, whilst simultaneously constructing new car parks for commuters in the city centre, is mutually incompatible.

The developments described show that $\mathrm{P}+\mathrm{R}$ is a niche phenomenon both in terms of use and in terms of there not being a well-developed regime behind it; of providers, knowledge institutions, business models, spokespersons and a community of experts. Both jurisdictions show that policy interest is unstable and often implicit. Despite the city specific contexts, we can discern two types of paths that $\mathrm{P}+\mathrm{R}$ goes after its introduction (see Figure 7).

Figure 7: Stylised process of $P+R$ introduction with two possible outcome paths

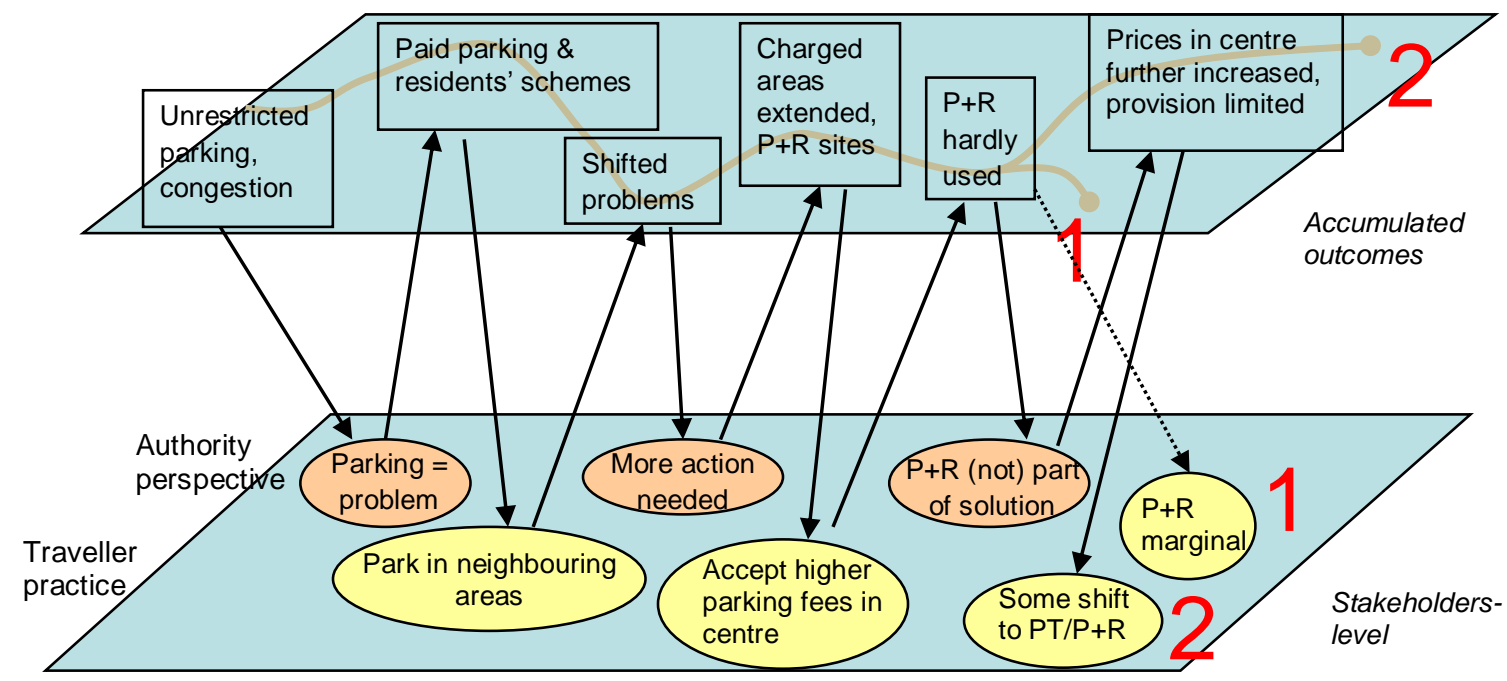

In most cities, $\mathrm{P}+\mathrm{R}$ was introduced after it turned out that the implementation of paid parking schemes and of resident parking permits was only partially solving problems (and mainly shifting problems to neighbouring areas). The initial niche of $\mathrm{P}+\mathrm{R}$ usage did not accumulate significantly by itself, since most car travellers still parked in the city centres, accepting the relatively higher fees. This condition put city councils at a crossroads. Some authorities saw this as proof that $\mathrm{P}+\mathrm{R}$ was not an ultimate solution for transport issues, and should not get too much attention. Correspondingly, there was little support for strong regime restricting and $\mathrm{P}+\mathrm{R}$ niche promoting policies in those cities. Car travellers accepted the (moderate) parking fees grudgingly and continued to park in the city centre, leaving the $\mathrm{P}+\mathrm{R}$ niche with insignificant modal share (Utrecht, Bristol ${ }^{12}$, Rotterdam). Other cities authorities seized the presence of $\mathrm{P}+\mathrm{R}$ sites as an opportunity to make push and pull policies increasingly stronger, arguing that the facilities provided an affordable alternative to car drivers. Here, car drivers became more reluctant to parking in the city centre, and a more significant share shifted to public transportation and or $\mathrm{P}+\mathrm{R}$ (Oxford, Amsterdam, York).

\footnotetext{
${ }^{12}$ In Bristol the tight local authority boundaries also played an important role, entailing difficulties to plan and develop new $\mathrm{P}+\mathrm{R}$ sites beyond the urban area.
} 
Nevertheless, in none of the cities the $\mathrm{P}+\mathrm{R}$ niches really threatened or undermined the central parking regime (at least not yet), and the latter shows a large extend of stability, with powerful actors behind it: parking garage operators and shop owners generally favouring central parking. Hence, the tendency of $\mathrm{P}+\mathrm{R}$ to trigger urban car mobility transition we find is low. $\mathrm{P}+\mathrm{R}$ facilities improve access to towns, and although there may be a significant increase in short public transportation trips as a result, there may also be growth in car travel (and car dominance) overall.

Whilst the general relationships identified in the analysis are likely to have considerable relevance for many cities, we note our case-studies were selected as being associated with innovative sustainable urban transport policies in their respective domestic contexts. Therefore, $\mathrm{P}+\mathrm{R}$ applications not accompanied by even the levels of push and pull factors identified in the six cases would be expected to demonstrate even lower effective pressure on car use. Moreover, the cities examined here are in the small-to-medium range. Megacities can be too complex in transport planning terms to promote targeted $\mathrm{P}+\mathrm{R}$ schemes of the nature and scale in the six cases. London, for example, has a policy presumption against providing $\mathrm{P}+\mathrm{R}$ within the metropolitan area (Parkhurst, 2004) and any additional capacity serving London would generally only be delivered at railway stations tens or hundreds of kilometres way for more general purposes than specifically serving London. At the other extreme, smaller cities often face particular problems of car dependence, such as low car traffic restraints and a weak and limited public transport offer: $\mathrm{P}+\mathrm{R}$ can therefore be expected to be ineffective both as a transport system and a sustainable mobility measure. Whilst the UK, and particularly the Netherlands, have strong traditions of land use planning, both countries have followed the neoliberal economic turn in recent decades, with some disintegration of land use and transport planning as a result. In the UK the regional tier of governance was recently abolished, with strategic planning now conducted at the subregional level, and led by economic growth-oriented Local Economic Partnerships. Jurisdictions with stronger regional governance and greater integration between urban car traffic and regional public transport policies are likely to provide a more effective context for deploying $\mathrm{P}+\mathrm{R}$ as a sustainable mobility measure.

\section{Conclusion}

Examination of our six case-studies did not indicate a particularly strong 'national character' to the interpretation and adoption of $\mathrm{P}+\mathrm{R}$ as a niche traffic management innovation, even if there were clear superficial differences, such as the exclusive use of bus transport in the UK and the reliance on rail in the Netherlands. Each of the cities had a distinctive policy frame and mode of implementation but analysis of the effectiveness of the schemes showed that three cities (two British, one Dutch) had implemented P+R with push and pull factors of sufficient potency to result in partial transformation away from the dominant parking regime.

Regarding our hypotheses we find that the $\mathrm{P}+\mathrm{R}$ niche promoting factors have limited value in sustainable mobility terms without the regime restricting factors being in place. As the cases of Rotterdam and Bristol show: it simply results in increased parking supply. Where both factors are absent, as in the case of Utrecht, $\mathrm{P}+\mathrm{R}$ use will be minimal. More 
subtly, the presence of both factors does not guarantee that $\mathrm{P}+\mathrm{R}$ becomes a numerically (rather than symbolically) significant mode: in all the cases of Oxford, York and Amsterdam, growth in overall public transport use has been a more important consequence of changes in transport policy than growth specifically in $\mathrm{P}+\mathrm{R}$ usage.

Our results show that policy to support $\mathrm{P}+\mathrm{R}$ is not straightforward but full of potential counter effectiveness. It needs an integrated policy approach to transport, encompassing (restricted) car use, (improved or improved access to) public transport, walking and cycling etc. and must be based on an integrated understanding of travel behaviour, infrastructures, operators and policy.

\section{References}

Bratzel, S. (2011) 'Ent-Emotionalisierung der Automobilität bei der jungen Generation? Neuere empirische Studien zum Auto im Wandel in Deutschland', Der KfzSachverständige, Vol. 6, pp.20-21.

Bundesverband CarSharing (bcs) (2014) Carsharing Boom Continues, Press Release, 27 February $2014 \quad$ [online] http://www.carsharing.de/sites/default/files/uploads/presse/pm_carsharingbilanz_2013_e nglisch.pdf (accessed 28 February 2014).

Calabrese, G. and Groupe d'études et de recherches permanent sur l'industrie et les salariés de l'automobile (GERPISA) (2012) The Greening of the Automotive Industry, Palgrave Macmillan, Basingstoke.

Canzler, W. and Knie, A. (2011) Einfach aufladen. Mit Elektromobilität in eine saubere Zukunft, Oekom Verlag, München.

European Commission (2011) Roadmap to a Single European Transport Area - Towards a Competitive and Resource Efficient Transport System, White Paper, EU COM 2011: 8 [online] http://eurlex.europa.eu/LexUriServ/LexUriServ.do?uri1/4COM:2011:0144:FIN:EN:PDF (accessed 20 March 2013).

European Union (EU) (2012) EU Transport in Figures, Statistical Pocketbook 2012 [online] http://ec.europa.eu/transport/factsfundings/statistics/doc/2012/pocketbook2012.pdf (accessed 27 February 2014).

Firnkorn, J. and Müller, M. (2011) 'What will be the environmental effects of new freefloating car-sharing systems? The case of car2go in Ulm', Ecological Economics, Vol. 70, No. 8, pp.1519-1528.

Geels, F.W., Kemp, R., Dudley, G. and Lyons, G. (2012) Automobility in Transition?: A Socio-technical Analysis of Sustainable Transport, Routledge, New York.

Grieco, M. and Urry, J. (2011) Mobilities New Perspectives on Transport and Society, Ashgate, Farnham, Burlington, VT [online] 
http://search.ebscohost.com/login.aspx?direct=true \&scope=site \&db=nlebk\&db=nlabk\&A $\mathrm{N}=411222$ (accessed 27 March 2014).

Herget, M. (2013) 'Familien auf dem Land - morgen noch mobil?', in Bundesanstalt für

Landwirtschaft und Ernährung (Hrsg.): Daseinsvorsorge in ländlichen Räumen unter Druck, pp.22-24, Bonn. S.

Hildermeier, J. and Villareal, A. (2014) 'Two ways of defining sustainable mobility: Autolib'and BeMobility', Journal of Environmental Policy \& Planning, Vol. 16, No. 1, pp.1-16 [online publication].

Joint Research Council (JRC) (2013) Paving the Way to Electrified Road Transport, Publicly Funded Research, Development and Demonstration Projects on Electric and Plug-in Vehicles in Europe, Alyona Zubaryeva, Christian Thiel [online] http://publications.jrc.ec.europa.eu/repository/ (accessed 5 March 2014).

Jullien, B. and Lung, Y. (2011) Industrie automobile: La croisée des chemins, La documentation française.?, Paris.

Lanzendorf, M. and Schönduwe, R. (2013) 'Urbanität und Automobilität: Neue Nutzungsmuster und Bedeutungen verändern die Mobilität der Zukunft', Geographische Rundschau, Vol. 65, No. 6, pp.34-41.

Mitchell, W.J., Borroni-Bird, C. and Burns, L.D. (2010) Reinventing the Automobile: Personal Urban Mobility for the 21st Century, Massachusetts Institute of Technology, Cambridge, Mass.

Parkhurst, G., Kemp, R., Dijk, M. and Henrietta, S. (2012) 'Intermodal personal mobility: a niche caught between two regimes', in Geels, F.W. et al. (2012): Automobility in transition? A Socio-technical Analysis of Sustainable Transport, pp.308-335, Routledge, New York 


\section{Appendix 1: Data sources}

Analyzed policy reports

\begin{tabular}{|c|c|}
\hline city & Report \\
\hline Amsterdam & $\begin{array}{l}\text { 2001a. Eindevaluatie P+R Transferium Arena. dienst Infrastructuur, Verkeer en Vervoer, Gemeente } \\
\text { Amsterdam, Amsterdam } \\
\text { 2001b. Parkeren is manoeuvreren. Nota Parkeerbeleid. Dienst Infrastructuur Verkeer \& Vervoer, } \\
\text { Gemeente Amsterdam, Amsterdam }\end{array}$ \\
\hline Rotterdam & $\begin{array}{l}\text { 1993. Verkeers- en Vervoersplan Rotterdam (VVPR). Gemeente Rotterdam, Rotterdam } \\
\text { 2005. Effectmonitor VVPR 2004. dS+V, afd. Verkeer \& Vervoer, Gemeente Rotterdam, Rotterdam } \\
\text { 2007. Effectmonitor VVPR 2006. dS+V, afd. Verkeer \& Vervoer, Gemeente Rotterdam, Rotterdam }\end{array}$ \\
\hline Utrecht & $\begin{array}{l}\text { 2003a. Onderzoek naar andere parkeervergunningssystemen } \\
\text { 2003b. Parkeren: een kwestie van kiezen. Parkeernota. Gemeente Utrecht, Utrecht }\end{array}$ \\
\hline Oxford & $\begin{array}{l}\text { 1993. Local Plan Review 1991-2001, Oxford City Council, Oxford } \\
\text { 2001. The City of Oxford Central Air Quality Management Area, Oxford City Council } \\
\text { 2004. Ten Quick Questions on Air Quality Issues in Oxford, brochure, Oxford City Council }\end{array}$ \\
\hline York & $\begin{array}{l}\text { 2006a. Local Transport Plan 2001-2006 Delivery Report. Committee Report 25/7/06. City of York, } \\
\text { York } \\
\text { 2006b. Local Transport Plan 2006-2011. City of York, York } \\
\text { 2009a. Car Parking In York. Committee Report 8/9/09. City of York, York } \\
\text { 2009b. Review of Public Bus Services in York. Committee Report 20/1/09. City of York, York }\end{array}$ \\
\hline Bristol & $\begin{array}{l}\text { 1996. A4 Bath Road, Bristol } 1996 \text { User Survey. Bristol City Council, Bristol } \\
\text { 2000. Bristol Local Transport Plan: Main Document. Bristol City Council, Bristol } \\
\text { 1997. Long Ashton Park \& Ride } 1997 \text { User Survey. Bristol City Council/North Somerset Council } \\
\text { 2006. Final Joint Local Transport Plan 2006/7-2010/11. West of England Partnership, Bristol } \\
\text { 2008. Joint Progress Review 2008. West of England Partnership, Bristol }\end{array}$ \\
\hline
\end{tabular}

